Send your letters to the Editor,

British Dental Journal,

64 Wimpole Street

London

W1G 8YS

Email bdj@bda.org

Priority will be given to letters less than 500 words long.

Authors must sign the letter, which

may be edited for reasons of space.

\section{SANCTIONS ERROR}

Sir, in the paper by Singh, Mizrahi and Korb, which reviewed cases that appeared before the GDC Professional Conduct Committee (BDJ 2009; 206: 217-223) there is an error relating to the sanctions which currently may be applied by the Committee, when a dental professional's fitness to practise is impaired (page 218).

Erasure [from the Register] is for not less than five years, and not for up to five years as stated. In fact, erasure is permanent and is not for any fixed term. However, an erased registrant may apply to the Council for restoration to the Register after not less than five years. The application must be approved by a further hearing of the Professional Conduct Committee.

A. S. Kravitz OBE, London DOI: 10.1038/sj.bdj.2009.480

\section{A SAFE MODALITY}

Sir, we read with considerable interest the paper by Malden et al. ${ }^{1}$ discussing dental extractions and the associated risk for osteonecrosis of the jaw (ONJ) development. The authors propose a useful risk classification of patients receiving bisphosphonates (BP), mainly based on prescription indication. There is a rationale in the proposed classification, since $0 \mathrm{NJ}$ is reported to be less frequent with nonmalignant prescription indications. ${ }^{2}$ The authors report that a dental extraction can increase this risk of ONJ by a factor of up to seven. However, they do not comment on two studies published last year which confirmed the association of dental extractions and ONJ development. ${ }^{3,4}$ The first study from our institution confirmed an at-least 16-fold increased risk for ONJ following dental extraction. ${ }^{4}$ The other, coming from the MD Anderson Cancer
Center, demonstrated a 10 to 53 -fold risk for ONJ following dental extraction. ${ }^{3}$

The authors propose that whenever possible, patients should be encouraged and counselled to stop smoking. Despite the well-known association of smoking with periodontal disease, based on existing evidence it may not be appropriate to recommend quitting smoking to reduce risk for ONJ. In the study from our institution, we were not able to detect an increased risk for ONJ among smokers. ${ }^{4}$ The latter study encompasses American Society of Clinical Oncology (ASCO) Level III evidence.

The authors propose that extractions in cases where discontinuation of bisphosphonates has been instigated for 12 months or more would be expected to carry a reduced risk of ONJ. In patients who are going to experience surgical treatment for $\mathrm{ONJ}$, discontinuation of BP is still a matter of debate. BP are reported to have an up to ten years long clearance time from calcified tissue., Some studies reported that besides having discontinued BP for at least six months prior to surgical treatment for ONJ, no obvious outcome improvement was recorded ${ }^{6}$ whilst others concluded that withdrawal is not recommended. ${ }^{5}$ A recent study included discontinuation in the treatment protocol, however, the authors could not answer whether discontinuation had a positive effect on the outcome. ${ }^{7}$ In a recent manuscript we describe a series of molecular mechanisms implicated in BP interaction with hard and soft tissues, which are thought to require minimal concentration of BP in the extra-cellular fluid, ${ }^{8}$ thereby suggesting that withdrawal of BP could hardly have some positive effect on outcome. Based on these data we have revised treatment protocols in our institution to exclude BP withdrawal and possibly prevent systemic disease deterioration following withdrawal, at least until further evidence is presented. Therefore, the authors' expectation that discontinuing BP could reduce risk for ONJ development, may not be supported by the existing evidence.

Malden et al. suggest that when possible, periodontal issues could be addressed prior to any extractions. ${ }^{1}$ Recent evidence by Estilo et al. ${ }^{9}$ and also unpublished data from our institution support this argument. Oral hygiene and periodontal disease were not found to be associated with increased risk for ONJ development and we therefore suggest that non-surgical periodontal treatment may be a safe modality.

\section{A. Kyrgidis, K. Vahtsevanos} Thessaloniki

1. Malden N, Beltes C, Lopes V. Dental extractions and bisphosphonates: the assessment, consent and management, a proposed algorithm. Br Dent J 2009; 206: 93-98.

2. Hess $L M$, Jeter J M, Benham-Hutchins $M$ et al. Factors associated with osteonecrosis of the jaw among bisphosphonate users. Am J Med 2008; 121: 475-483.e3.

3. Hoff A O, Toth B B, Altundag K et al. Frequency and risk factors associated with osteonecrosis of the jaw in cancer patients treated with intravenous bisphosphonates. J Bone Miner Res 2008; 23: 826-836.

4. Kyrgidis A, Vahtsevanos K, Koloutsos G et al. Biphosphonate related osteonecrosis of the jaws: risk factors in breast cancer patients. A case control study. J Clin Oncol 2008; 26: 4634-4638.

5. Lenz J H, Steiner-Krammer B, Schmidt W et al. Does avascular necrosis of the jaws in cancer patients only occur following treatment with bisphosphonates? J Craniomaxillofac Surg 2005; 33: 395-403.

6. Migliorati C A, Schubert M M, Peterson D E et al. Bisphosphonate-associated osteonecrosis of mandibular and maxillary bone: an emerging oral complication of supportive cancer therapy. Cancer 2005; 104: 83-93.

7. Wutzl A, Biedermann E, Wanschitz F et al. Treatment results of bisphosphonate-related osteonecrosis of the jaws. Head Neck 2008; 30: 1224-1230.

8. Kyrgidis A, Triaridis S, Antoniades K. Effects of bisphosphonates on keratinocytes and fibroblasts may have a role in the development of osteonecrosis of the jaw. Biosci Hypotheses 2009; in press.

9. Estilo C L, Van Poznak C H, Wiliams T et al. 
Osteonecrosis of the maxilla and mandible in patients with advanced cancer treated with bisphosphonate therapy. Oncologist 2008; 13: 911-920.

N. Malden, C. Beltes and V. Lopes respond: We thank Drs Kyrgidis and Vahtsevanos for their constructive criticism.

One of our main aims with the paper was to support general practitioners in the provision of dental treatment (particularly tooth extractions) in the low risk bisphosphonate group. We accept the high incidence of reported extraction associated BONJ cases from Greece but observe that these have almost exclusively been reported from the high risk (malignancy) group. Compared to a dental extraction a smoking habit may be a relatively weak risk factor for development of BONJ. The study referenced by Kyrgidis et al. (ref 4) included 20 subjects with ONJ with 40 controls and may not include an adequate subject number to demonstrate a possible link between BONJ and smoking (under-powered study). In consideration of the association of smoking and dry socket a recent study ${ }^{1}$ looked at $>800$ extractions in 469 subjects and was convincing in establishing a link with dry socket development.

More powerful studies looking at smoking and BONJ will no doubt follow in time. In the UK clinicians are under an obligation to counsel patients regarding smoking cessation and we would consider it a part of the informed consent process prior to any surgical procedure.

Our comments on drug discontinuation were primarily aimed at the low risk (alendronic acid) group and we apologise for any ambiguity. Ten years clearance time? Once bisphosphonates have been administered it is unlikely that they will ever be completely cleared from the skeleton, but this is of no relevance. The following paper which we referenced in our original article is a multi-centre double blind randomised controlled trial; it looked at the effects of continuing or stopping alendronic acid after five years of administration..$^{2}$ It demonstrated a gradual but immediate sustained increase in the level of bone turn-over markers from the time of discontinuation. At five years discontinuation of alendronate, bone turnover had returned to close to that of pretreatment levels (ten years previously). Now we accept that these marker levels are giving a general picture of skeletal turnover and may not be representative of what is happening to the jaws. The mandible and maxilla may have been preferentially and uniquely affected and may not be sharing in a recovery of bone turnover. It was interesting, however, that the FLEX trial did not show that the recovery of bone turnover was accompanied by a significant decline in bone mineral density, BMD or an increase in low impact fracture risk. In such cases the benefit to the jaws of drug discontinuation could be judged to outweigh the risks associated with systemic disease deterioration. However, in the high risk (malignancy group) the potential benefit of drug discontinuation to the jaws will generally be out-weighed by the risks of systemic disease deterioration. Case by case multidisciplinary assessment may be prudent.

We consider that these arguments highlight the need for us to clearly distinguish between the low and high risk groups when discussing management protocols. In fact one could argue that they should be considered as separate disease entities. The more challenging group for us at the moment, as mentioned in our paper, is the intermediate cases who are often receiving steroids and possibly cytotoxic drugs for non-malignant conditions.

We await further publications from $\mathrm{Dr}$ Kyrgidis's unit with interest.

1. Nusair YM, Younis M H. Prevalence, clinical picture, and risk factors of dry socket in a Jordanian dental teaching center. J Contemp Dent Pract 2007; 8:53-63.

2. Black D M, Schwartz A V, Ensrud KE Et al. Effects of continuing or stopping alendronate after 5 years of treatment. The Fracture Intervention Trial Longterm Extension (FLEX): A Randomized Trial. JAMA 2006; 296: 2927-2938.

DOI: $10.1038 /$ sj.bdj.2009.481

\section{INTERAGENCY WORKING}

Sir, regarding the case report of selfinjurious behaviour (SIB) presenting as gingivitis artefacta major (BDJ 2009; 206: 129-131) the authors mention the patient's non-attendance at CAMHS and dental appointments delaying appropriate intervention for a considerable period. This may have been avoided through effective communication with the CAMHS team at the time of referral and when the young person did not attend dental appointments. The authors also mention the patient's difficult background (neglect etc) but do not make clear whether social services were involved and if not this may have been appropriate in light of the presenting complaint, non-attendance at appointments and the patient's living arrangements. It is important to remember that failure to attend appointments can in itself be a child protection issue if it affects wellbeing. It is essential that dental health professionals have adequate child protection training and are aware of how to efficiently access their local Child and Adolescent Mental Health Services. The Laming report (The Victoria Climbié Inquiry) states that effective interagency working and communication are essential to safeguarding children.

\section{K. Nisar, N. Aslam} By email

Dr Christopher Millen responds on behalf of his co-authors: We would like to thank Drs Nisar and Aslam for their comments. We are in complete agreement with their statements regarding the safeguarding of vulnerable children and effective interagency communication in relation to child protection. The need for this approach has been highlighted in a number of guidelines over recent years ${ }^{1,2}$ and thus as a dental team we should both be aware of our responsibilities and have a heightened awareness of the signs and symptoms of child abuse. The dental team's role in the care of children and adolescents presenting with self harm is perhaps less well defined. Children and adolescents presenting with possible or actual self-harm are vulnerable and have complex needs, and thus there is also a need for an awareness of the presenting signs and symptoms and effective close interagency communication.

In presenting this case of self harm in a competent 15-year-old who accessed unscheduled care, the authors sought to raise the awareness of the dental team to one possible presentation of oral self-harm and to highlight management difficulties which can arise. Advice as to the appropriate path of referral was sought prior to making the referral, but, in this instance, there was a breakdown in communication. We would wholeheartedly agree with Drs Nisar and Aslam that there is a need for close follow up and continued interagency communication in such cases, beyond the usual 'automated' 
process. The need for an integrated care pathway for onward care when a child or adolescent presents at an emergency care site has recently been highlighted. ${ }^{3}$ It would seem appropriate that Local Child Protection Referral Pathways should also include guidance as to where the dental team should source advice for concerns about cases of possible self harm.

1. Health for all children: Guidance and principles of practice for professional staff, Department of Health, Social Services and Public Safety, October 2006.

2. Harris J, Sidebotham P, Welbury Ret al. Child protection and the dental team. An introduction to safeguarding children in dental practice. Sheffield: Committee of Postgraduate Dental Deans and Directors, 2006. www.cpdt.org.uk

3. Emergency Care Framework for Children and Young People in Scotland, Scottish Executive, Edinburgh 2006.

DOI: 10.1038/sj.bdj.2009.482

\section{DENTAL ACCESS CENTRES}

Sir, I found the discussion section of the article on Dental Access Centres (BDJ 2009; 206: 257-261) by Milsom et al. to be contradicting itself.

After identifying the DAC population as being more likely to prefer symptomatic attendance and to not view regular care as a priority it goes on to talk about the opportunity in 'high street' practices for these patients to develop commitment to a more holistic approach. This, from a group of patients that the authors admit elect not to be pressurised into developing long term professional relationships and who prefer safety net services. This just does not make sense. The conclusions are also totally contrary to the Government's notion of patient choice.

The study identified DAC patients as generally coming from disadvantaged localities, to be exempt patient charges and that their dental health is substantially poorer. It would be interesting to have included how good they were in keeping appointments compared to those patients attending 'high street' dentists. Such a study might help to explain some of the dental public health concerns.

\section{E. Gordon, Finchley}

Dr Keith Milsom responds: Thank you for your letter in response to the article on Dental Access Centres.

The study identified differences in characteristics between patients attending 'high street' dentists and DACs, with DAC patients more likely to:
- Come from more disadvantaged backgrounds

- Have decay

- Prefer symptomatic attendance.

The conclusions drawn by the authors appear to have raised in the mind of the respondent something of a dilemma. Should the 'high street' NHS dentist's role be restricted to addressing the needs of those patients whose dental health is good, who attend regularly and who are not exempt from dental charges, leaving the care of the less dentally motivated in society to others? It could be argued that under the terms of the new dental contract, treatment of irregularly attending patients with relatively high decay rates is currently unattractive for 'high street' dentists. This issue is addressed in the article and suggestions for change are considered.

DACs were set up at a time when the availability of NHS dental care was diminishing and there was little the Government could do to encourage NHS dentists to accept new patients. Now that we have a new dental contract the situation is quite different. PCTs are able to engage with the local profession in the pursuit of dental services that meet the needs of all those wishing to access NHS care. Given this new flexibility, the role of the DAC should be revisited. It may be that currently short term symptomatic dental care for poorly motivated individuals is not attractive for many 'high street' dentists, but perhaps this problem should be addressed via development of the dental contract, rather than by perpetuating a separate and often expensive alternative service.

DOI: 10.1038/sj.bdj.2009.483

\section{SCANDAL}

Sir, I write in reference to the letter from Dr M. B. Rothschild Rights and responsibilities (BDJ 2009; 206: 338). I sympathise with Dr Rothschild's - and his patient's - predicament but it is not new. I wrote in 2000 (Volume 190 issue 6) in response to Dr S. Orlans' earlier letter on precisely the same issue.

Nine years later nothing has been done to alleviate the problem. Bearing in mind the list of acceptable telephone prescribers that pharmacists have been given by the Royal Pharmaceutical Society the exclusion of GDC registered dentists is really nothing short of scandal.

Can the BDA explain what the General Practice Committee is for if not to address exactly such difficulties as this? Do they listen to members or are they so fixed on their own agenda that they have lost all flexibility to deal with the real concerns of members and clear anomalies in the system imposed on us?

There are colleagues who have resigned over less significant matters.

\section{P. J. Newman Brown, Tunbridge Wells DOI: 10.1038/sj.bdj.2009.484}

\section{INSTRUMENT FOR CONTROL}

Sir, having just read Dr Rothschild's letter (BDJ 2009; 206: 338), I have to add my ha'pennyworth. It is my opinion that the GDC, far from being an independent arbiter of professional standards, has become an instrument for control, by the Government, via the Department of Health. This view is, in my opinion, supported by a recent article by Roger Matthews in Dentistry and has been my experience whilst practising. When asked for an opinion about practice standards, it seemed that the standard reply has been, to paraphrase, 'Try it and see. If you are incorrect in your interpretation we'll screw you.'

Being of a lower deck mentality I was never content with the 'passing off' that the GDC attempted when I asked for interpretations of their directives and I used the good offices of my MP to get a direct answer. In both cases it transpired that my opinion was correct, but I was left with the feeling that the worth of the GDC in its allotted role of protecting patients was severely diminished. It seemed to me that it was there simply to deal with any transgressors rather than give clear and unambiguous guidance to ethical practitioners.

I am glad to say I am retired. The nonsense of the present GDC (once again a product of political correctness), has determined that the profession of dentistry will decline to be, simply, an outreach of the cosmetic industry.

This letter will do nothing to stem that disaster, sad when you think how hard our 'professionalism' was won, but at least I've had my say.

\section{W. Quirke}

By email

DOI: 10.1038/sj.bdj.2009.485 